\title{
Treatment patterns and outcomes in older women with early breast cancer: a population-based cohort study in China
}

\author{
Xu Liu', Dan Zheng', Yanqi Wu' ${ }^{1}$ Chuanxu Luo ${ }^{1}$, Yu Fan', Xiaorong Zhong ${ }^{1,2^{*}}$ and Hong Zheng ${ }^{1,2^{*}}$
}

\begin{abstract}
Background: Despite the proportion of elderly breast cancer patients has been consistently increasing, the optimal treatment modalities for this population have not been well explored. We summarized the treatment outcomes of these patients in our hospital.

Methods: Older patients with early breast cancer were identified from the Breast Cancer Information Management System at West China Hospital, Sichuan University (2000-2019). We compared tumor characteristics and treatment outcomes between the older group (65-74 years old) and the elderly group ( $\geq 75$ years old). The Kaplan-Meier and Cox regression analysis were conducted to determine significant prognostic factors.

Results: In total, 1094 patients were included. The median follow-up time for this cohort was 59 months. The majority of patients underwent surgery and benefited from surgical treatment. Elderly group patients were less likely to receive adjuvant chemotherapy or postmastectomy radiotherapy (PMRT) compared to the older group. However, adjuvant chemotherapy was associated with improved overall survival (OS) (hazard ratio [HR] 0.521, 95\%

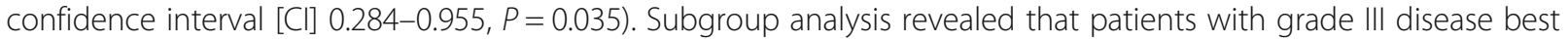
benefited from adjuvant chemotherapy. PMRT offered a significant improvement in local disease control, but not in OS. Furthermore, endocrine therapy improved the OS of HR-positive patients (HR 0.440, 95\% $0.261-0.741, P=$ 0.002), especially for cases aged 65-74 years. Also, receipt of trastuzumab in HER2-positive patients was associated with better OS (HR 0.168, 95\% Cl 0.029-0.958, $P=0.045$ ).

Conclusions: Our findings suggest that surgery, adjuvant chemotherapy, endocrine and targeted therapy are associated with improved OS in older breast cancer patients. Moreover, clinicopathological characteristics should be comprehensively considered when making treatment decisions for these patients.
\end{abstract}

Keywords: Breast cancer, Elderly women, Adjuvant therapy, Overall survival

\section{Background}

Breast cancer is the most common malignancy in women worldwide, and the incidence rates have been rising for most countries in transition over the last decades [1]. From 2011 to 2015, the number of new breast cancer

\footnotetext{
*Correspondence: zhongxiaorong@126.com; hzheng@scu.edu.cn 'Laboratory of Molecular Diagnosis of Cancer, Clinical Research Center for Breast, West China Hospital, Sichuan University, Chengdu, China Full list of author information is available at the end of the article
}

cases occurred in Chinese female increased from 248,620 to 304,000 , and the age-specific incidence rates peaked at the age group of 55-60 [2, 3]. During the last three decades, the peak of incidence has been gradually shifting to older age group, $27.0 \%$ of patients with breast cancer are estimated to be 65 years or older in China by $2030[4,5]$.

However, despite the increasing proportion of elderly patients with breast cancer, data on treatments and outcomes for this patient population are limited, partly

(C) The Author(s). 2021 Open Access This article is licensed under a Creative Commons Attribution 4.0 International License, which permits use, sharing, adaptation, distribution and reproduction in any medium or format, as long as you give appropriate credit to the original author(s) and the source, provide a link to the Creative Commons licence, and indicate if changes were made. The images or other third party material in this article are included in the article's Creative Commons licence, unless indicated otherwise in a credit line to the material. If material is not included in the article's Creative Commons licence and your intended use is not permitted by statutory regulation or exceeds the permitted use, you will need to obtain permission directly from the copyright holder. To view a copy of this licence, visit http://creativecommons.org/licenses/by/4.0/ The Creative Commons Public Domain Dedication waiver (http://creativecommons.org/publicdomain/zero/1.0/) applies to the data made available in this article, unless otherwise stated in a credit line to the data. 
because elderly patients have been under-represented in most breast cancer treatment trials [6]. Previous studies have even yielded inconsistent results, leading to challenges for clinicians in managing elderly patients. For instance, some studies showed that reduced treatment did not impact survival outcomes [7], while others found that decreased survival was associated with the undertreatment in elderly breast cancer patients [8, 9]. Moreover, the guidelines for their younger counterparts are difficult to extrapolate to older patients, who need to be considered with multiple factors in decision-making, such as functional status, comorbidities, and life expectancy. More researches on breast cancer in older people are needed to improve outcomes and prepare for extensive demand for treatment of this rapidly growing population [10].

Therefore, this study aimed to investigate the tumor characteristics and the associations between treatment modalities and survival in a large population-based cohort of patients over 65 years of age with early breast cancer.

\section{Methods \\ Study population}

Breast cancer information management system (BCIMS) of West China Hospital, Sichuan University, contains over 16,000 breast cancer patient cases dating back to 1989 and prospectively records demographic and clinicopathologic characteristics, medical history, diagnosis, laboratory results and treatments, as described previously [11]. Female breast cancer patients diagnosed between 2000 and 2019 and who were over 65 years of age at initial diagnosis were identified from BCIMS $(n=$ $1145)$. Patients with synchronous distant metastases $(n=44)$ or those lacking essential registry data $(n=7)$ were excluded. In total, 1094 consecutive female patients were included in this cohort. Ethical approval for this study was provided by the Clinical Test and Biomedical Ethics Committee (approval number:2012130), West China Hospital, Sichuan University. And all methods were performed in accordance with the Declaration of Helsinki. Informed consent was obtained from all patients at the time of initial diagnosis.

\section{Data collection}

Demographic, clinicopathologic, and treatment information were derived from the BCIMS. Demographic records included age at diagnosis and body mass index (BMI). The BMI cutoffs are based on the standards recommended in the Guidelines for Prevention and Control of Overweight and Obesity in Chinese Adults [12]. Clinicopathological factors included tumor histology, $\mathrm{T}$ stage, axillary lymph node status, clinical stage, hormone receptor (HR) status, Human epidermal growth factor receptor-2 (HER2) status, Ki-67 index and tumor grade. The positivity of estrogen receptor (ER) and progesterone receptor (PR) was determined by immunohistochemistry (IHC) according to the Guidelines for Testing of ER and PR in Breast Cancer [13]. HR was considered positive if either ER or PR was positive. HER2 status was determined by IHC and fluorescence in situ hybridization (FISH) following the Guidelines for HER2 Detection in Breast Cancer [14]. The threshold of Ki-67 was positivity in 20\% of cells: low Ki-67 [ $\leq 20 \%$ ], high Ki-67 [> 20\%]. Histological tumor grade was evaluated by the Nottingham grading system and divided into the following categories: grade I, grade II and grade III. The treatment modalities included surgery, neoadjuvant chemotherapy, adjuvant chemotherapy, radiotherapy, endocrine therapy, and targeted therapy.

\section{Follow-up and study outcomes}

The follow-up was conducted every 4 months in the first 3 years after diagnosis, every 6 to 12 months in the fourth and fifth years, and annually after 5 years. Followup was operated by office visit, telephone, email, or postal contact, as described in our previous report [15]. Lost to follow-up was defined as failure to contact with the patient on $>2$ consecutive occasions.

Overall survival (OS) was calculated as the time from the date of diagnosis to the date of death from any cause. Disease free survival (DFS) was defined as the time from diagnosis to the first event (death from any cause, locoregional recurrence, distant metastasis and second primary breast cancer). Locoregional recurrence (LRR) was defined as recurrence in the ipsilateral chest wall, supraclavicular and infraclavicular areas, axilla, and internal mammary region. Locoregional recurrence-free survival (LRFS) was counted from surgery date to the date of LRR as the first event [16]. Patients alive without any cancer recurrence were censored on the date of the last follow-up.

\section{Statistical analysis}

Data are presented as medians or proportions. Descriptive statistics were used to analyze the clinical and demographic characteristics of the population. According to the nature of the variable, the Chi-square test, Fisher's exact test or Student's t-test was used to compare the distribution of baseline characteristics among age groups. Survival curves were estimated using the Kaplan-Meier method, and log-rank tests were performed for comparison of survival outcomes. Cox proportional hazards regression models were used to determine the significant prognostic factors of survival and expressed as hazard ratio (HR) with 95\% confidence interval (CI). Missing data were processed using multiple imputation. All statistical tests were 2tailed and $P$ values less than 0.05 were considered to be statistically significant. All statistical analyses were 
performed using IBM SPSS statistics software (version 23.0) and R software (version 3.5.1; R Foundation).

\section{Results}

\section{Patients characteristics}

A total of 1094 women with early-stage breast cancer were included in the analysis. The median age at diagnosis of breast cancer was 68 years (range 65-94 years) for the whole patients. The demographic and tumor characteristics of patients are summarized in Table 1 . The majority of patients had normal BMI (40.2\%). Overall, invasive ductal carcinoma was the most common histological type (78.9\%). And most of tumors were diagnosed at stage II (46.7\%), with positive HR status $(69.2 \%)$ and negative HER2 status (70.9\%).

All patients were categorized into two subgroups based on their age at diagnosis: the older group (65-74 years old) versus the elderly group ( $\geq 75$ years old). The total number of older group patients was 930 (85.0\%), and that of elderly group was $164(15.0 \%)$. The elderly group patients were more likely to be underweight when compared with the older group $(P<0.001)$. No significant differences were found between two age groups in terms of tumor histological type, clinical stage, T stage, $\mathrm{N}$ stage, HR status, HER2 status, molecular subtype, Ki67 level and tumor grade.

\section{Follow-up and survival outcomes}

The median follow-up time for this cohort was 59 months. Death events differed between the two groups, $102(11.0 \%)$ cases died in the older group, and 41 $(25.0 \%)$ cases died in the elderly group during the follow-up period $(P<0.001)$. However, recurrence and metastasis rate was not different between the two groups (9.1\% vs $10.4 \%, P=0.619)$.

In this cohort, the 5-year and 10-year OS rates of all patients were $89.0 \%$ and $77.5 \%$. Table 2 shows the results of univariate and multivariate analysis of OS in all patients. In the univariate analysis, patients who aged over 75 years, had underweight, diagnosed at stage III, negative for HR status, with high Ki-67 level or with poorly differentiated tumor grade showed trends toward worse survival (all $P<0.05$ ). Whereas, in the multivariate analysis, only age older than 75 years $(\mathrm{HR}=1.935$, 95\% CI 1.109-3.376, $P=0.020)$, underweight $(\mathrm{HR}=$ 3.262, 95\% CI 1.526-6.974, $P=0.002)$, stage III (HR = 6.215, 95\% CI 2.713-14.235, $P<0.001)$ and high Ki-67 level $(\mathrm{HR}=1.900,95 \% \mathrm{CI} 1.065-3.388, P=0.030)$ were independently associated with poor survival. Furthermore, we performed multivariate Cox regression analysis for DFS and found only underweight and stage III were independent risk factors of DFS for the entire population (Additional file 1: Table S1).

\section{Treatment patterns}

\section{Surgery}

The majority of patients $(1043 / 1094,95.3 \%)$ in this cohort underwent surgery (Table 3). Surgery rates were high for both groups $(95.1 \%$ vs. $97.0 \%$, respectively, $P=$ 0.288). Of those who underwent surgery, 963 patients $(92.3 \%)$ received modified radical mastectomy, while 54 patients $(5.2 \%)$ received radical mastectomy, very few patients $(n=26,2.5 \%)$ were treated with breast conserving surgery or palliative surgery.

In the survival analysis, patients who underwent surgery had longer survival than those who did not (5-year OS rate: $90.0 \%$ vs. $60.0 \%, P<0.001$, Fig. 1 a; 5 -year DFS rate: $83.8 \%$ vs. $61.5 \%, P<0.001$, Additional file 2 : Fig. $\mathrm{S} 1 \mathrm{~A})$. And there was no significant difference in OS between patients who received modified radical mastectomy and those did radical mastectomy when clinical stage was considered (data not shown). In subgroup analyses, the effect of surgery on OS and DFS in older breast cancer patients was consistently favorable across all subgroups (all $\mathrm{HR}<1.0$, Fig. $2 \mathrm{a}$ and Additional file 2: Fig. S2A). After adjusting for age and clinical stage, surgery was an independent prognostic factor associated with a significant reduction in mortality (HR 0.476, 95\% CI $0.250-0.904, P=0.023$, Table 4 ). In addition, surgery was also significantly associated with improved DFS (Additional file 1: Table S2).

\section{Adjuvant and neoadjuvant chemotherapy}

We analyzed the efficacy of adjuvant chemotherapy in older patients who had undergone surgery. Among them, most patients (68.7\%) received adjuvant chemotherapy, but elderly group patients were less likely to receive it when compared with those in the older group (35.8\% vs $74.7 \%, P<0.001$, Table 3 ). With regard to the type of chemotherapy, most patients were treated with anthracyclines and/or taxanes, especially for the older group. In Kaplan-Meier analysis, adjuvant chemotherapy seemed to have no effect on OS and DFS (Fig. 1b and Additional file 2: Fig. S1B). However, multivariate analysis showed that adjuvant systemic chemotherapy might be associated with improved survival (OS: HR 0.521, 95\% CI 0.284-0.955, $P=0.035$, Table 4; DFS: Additional file 1: Table S2). In the subgroup analysis, adjuvant chemotherapy could offer significant survival benefit for patients with grade III or stage II disease (OS: HR 0.487, 95\% CI 0.269-0.881, $P=0.015$, Fig. 2b; DFS: Additional file 2: Fig. S2B).

According to current guideline for neoadjuvant chemotherapy in breast cancer, we only assessed the effect of neoadjuvant chemotherapy on older patients staged at II or III $(n=734)$. Among these patients, only $90(12.3 \%)$ cases received neoadjuvant chemotherapy, including $83(13.2 \%)$ cases in the older group and $7(6.7 \%)$ 
Table 1 Demographic and tumor characteristics of patients by age group

\begin{tabular}{|c|c|c|c|c|}
\hline Characteristics & $\begin{array}{l}\text { Total } \\
N=1094 \\
\text { n (\%) }\end{array}$ & $\begin{array}{l}\text { Older group } \\
N=930 \\
\mathrm{n}(\%)\end{array}$ & $\begin{array}{l}\text { Elderly group } \\
N=164 \\
\text { n (\%) }\end{array}$ & $P$ \\
\hline \multicolumn{5}{|l|}{ Age at diagnosis (years) } \\
\hline Median (range) & $68(65-94)$ & $68(65-74)$ & $77(75-94)$ & \\
\hline Body mass index $\left(\mathrm{Kg} / \mathrm{m}^{2}\right)$ & & & & $<0.001$ \\
\hline Underweight $(<18.5)$ & $48(4.4)$ & $33(3.5)$ & $15(9.1)$ & \\
\hline Normal (18.5-23.9) & $440(40.2)$ & $370(39.8)$ & $70(42.7)$ & \\
\hline Overweight (24.0-27.9) & $310(28.3)$ & $278(29.9)$ & $32(19.5)$ & \\
\hline Obese ( $\geq 28.0$ ) & $94(8.6)$ & $86(9.2)$ & $8(4.9)$ & \\
\hline Unknown $^{a}$ & $202(18.5)$ & $163(17.5)$ & $39(23.8)$ & \\
\hline Histology & & & & 0.248 \\
\hline DCIS & $86(7.9)$ & $68(7.3)$ & $18(11.0)$ & \\
\hline IDC & $863(78.9)$ & 739 (79.5) & $124(75.6)$ & \\
\hline Other & $97(8.9)$ & $81(8.7)$ & $16(9.8)$ & \\
\hline Unknown ${ }^{a}$ & $48(4.4)$ & $42(4.5)$ & $6(3.7)$ & \\
\hline Clinical stage & & & & 0.440 \\
\hline $0-1$ & $269(24.6)$ & $223(24.0)$ & $46(28.0)$ & \\
\hline$\|$ & $511(46.7)$ & $441(47.4)$ & $70(42.7)$ & \\
\hline III & $269(24.6)$ & $230(24.7)$ & $39(23.8)$ & \\
\hline Unknown ${ }^{\mathrm{a}}(\mathrm{I}-\mathrm{III})$ & $45(4.1)$ & $36(3.9)$ & $9(5.5)$ & \\
\hline T stage & & & & 0.455 \\
\hline$\leq \mathrm{T} 1$ & $394(36.0)$ & $333(35.8)$ & $61(37.2)$ & \\
\hline $\mathrm{T} 2$ & $525(48.0)$ & $454(48.8)$ & $71(43.3)$ & \\
\hline T3-T4 & $125(11.4)$ & $103(11.1)$ & $22(13.4)$ & \\
\hline Unknown $^{a}$ & $50(4.6)$ & $40(4.3)$ & $10(6.1)$ & \\
\hline $\mathrm{N}$ stage & & & & 0.109 \\
\hline No & $583(53.3)$ & $485(52.2)$ & 98 (59.8) & \\
\hline N1 & $302(27.6)$ & $260(28.0)$ & $42(25.6)$ & \\
\hline N2 & $112(10.2)$ & $103(11.1)$ & $9(5.5)$ & \\
\hline N3 & $97(8.9)$ & $82(8.8)$ & $15(9.1)$ & \\
\hline HR status & & & & 0.815 \\
\hline Positive & $757(69.2)$ & $641(68.9)$ & $116(70.7)$ & \\
\hline Negative & 305 (27.9) & $260(28.0)$ & $45(27.4)$ & \\
\hline Unknown ${ }^{a}$ & $32(2.9)$ & $29(3.1)$ & $3(1.8)$ & \\
\hline HER2 status & & & & 0.127 \\
\hline Positive & $153(14.0)$ & $137(14.7)$ & $16(9.8)$ & \\
\hline Negative & 776 (70.9) & 658 (70.8) & 118 (71.9) & \\
\hline Unknown $^{a}$ & $165(15.1)$ & $135(14.5)$ & $30(18.3)$ & \\
\hline Subtype & & & & 0.329 \\
\hline $\mathrm{HR}+\mathrm{HER} 2-$ & $584(53.4)$ & 499 (53.7) & $85(51.8)$ & \\
\hline $\mathrm{HR}+\mathrm{HER} 2+$ & $76(6.9)$ & $68(7.3)$ & $8(4.9)$ & \\
\hline HR-HER2+ & $77(7.0)$ & $69(7.4)$ & $8(4.9)$ & \\
\hline HR-HER2- & $188(17.2)$ & 155 (16.7) & $33(20.1)$ & \\
\hline Unknown $^{a}$ & $169(15.4)$ & 139 (14.9) & $30(18.3)$ & \\
\hline
\end{tabular}


Table 1 Demographic and tumor characteristics of patients by age group (Continued)

\begin{tabular}{|c|c|c|c|c|}
\hline Characteristics & $\begin{array}{l}\text { Total } \\
N=1094 \\
\text { n (\%) }\end{array}$ & $\begin{array}{l}\text { Older group } \\
N=930 \\
\mathrm{n}(\%)\end{array}$ & $\begin{array}{l}\text { Elderly group } \\
N=164 \\
\mathrm{n}(\%)\end{array}$ & $P$ \\
\hline Ki-67 level & & & & 0.654 \\
\hline Low ( $\leq 20 \%)$ & $466(42.6)$ & $400(43.0)$ & $66(40.2)$ & \\
\hline High (> 20\%) & $467(42.7)$ & $396(42.6)$ & $71(43.3)$ & \\
\hline Unknown $^{a}$ & $161(14.7)$ & $134(14.4)$ & $27(16.5)$ & \\
\hline Grade & & & & 0.594 \\
\hline$|-| \mid$ & 337 (30.8) & $292(31.4)$ & $45(27.4)$ & \\
\hline III & $373(34.1)$ & $318(34.2)$ & 55 (33.5) & \\
\hline Unknown $^{a}$ & $384(35.1)$ & $320(34.4)$ & $64(39.0)$ & \\
\hline
\end{tabular}

Abbreviations: DCIS ductal carcinoma in situ, IDC invasive ductal carcinoma, HR hormone receptor, HER2 human epidermal growth factor receptor 2 a: Unknown values were excluded during chi-square tests

Table 2 Univariate and multivariate analysis of overall survival in all breast cancer patients

\begin{tabular}{|c|c|c|c|c|}
\hline \multirow[t]{2}{*}{ Variable } & \multicolumn{2}{|l|}{ Univariate analysis } & \multicolumn{2}{|l|}{ Multivariate analysis } \\
\hline & $\mathrm{HR}^{\mathrm{a}}(95 \% \mathrm{Cl})$ & $P$-value & $\mathrm{HR}^{\mathrm{a}}(95 \% \mathrm{Cl})$ & $P$-value \\
\hline \multicolumn{5}{|l|}{ Age, years } \\
\hline $65-74$ & 1 & & 1 & \\
\hline$\geq 75$ & $2.074(1.442-2.983)$ & $<0.001$ & 1.935 (1.109-3.376) & 0.020 \\
\hline \multicolumn{5}{|l|}{$\mathrm{BMl}, \mathrm{kg} / \mathrm{m}^{2}$} \\
\hline $18.5-23.9$ & 1 & & 1 & \\
\hline$<18.5$ & $2.995(1.586-5.655)$ & 0.001 & $3.262(1.526-6.974)$ & 0.002 \\
\hline$>23.9$ & $1.161(0.731-1.844)$ & 0.527 & $0.918(0.498-1.693)$ & 0.784 \\
\hline \multicolumn{5}{|l|}{ Histology } \\
\hline DCIS & 1 & & & \\
\hline IDC & $1.611(0.817-3.177)$ & 0.169 & & \\
\hline Other & $1.313(0.544-3.169)$ & 0.545 & & \\
\hline \multicolumn{5}{|l|}{ Clinical stage } \\
\hline $0-1$ & 1 & & 1 & \\
\hline$\|$ & $1.172(0.704-1.951)$ & 0.542 & $1.089(0.453-2.616)$ & 0.850 \\
\hline III & $5.275(3.259-8.538)$ & $<0.001$ & $6.215(2.713-14.235)$ & $<0.001$ \\
\hline \multicolumn{5}{|l|}{ HR status } \\
\hline Negative & 1 & & 1 & \\
\hline Positive & $0.672(0.471-0.958)$ & 0.028 & $0.748(0.442-1.269)$ & 0.282 \\
\hline \multicolumn{5}{|l|}{ HER2 status } \\
\hline Negative & 1 & & & \\
\hline Positive & 1.167 (0.685-1.990) & 0.570 & & \\
\hline \multicolumn{5}{|l|}{ Ki-67 level } \\
\hline Low $(\leq 20 \%)$ & 1 & & 1 & \\
\hline High (> 20\%) & $2.102(1.441-3.064)$ & $<0.001$ & $1.900(1.065-3.388)$ & 0.030 \\
\hline \multicolumn{5}{|l|}{ Grade } \\
\hline$|-| \mid$ & 1 & & 1 & \\
\hline III & $1.747(1.105-2.760)$ & 0.017 & 1.047 (0.582-1.883) & 0.879 \\
\hline
\end{tabular}


Table 3 Treatment patterns in older breast cancer patients

\begin{tabular}{|c|c|c|c|c|}
\hline Treatment & $\begin{array}{l}\text { Total } \\
\mathrm{N}(\%)\end{array}$ & $\begin{array}{l}\text { Older group } \\
\mathrm{N}(\%)\end{array}$ & $\begin{array}{l}\text { Elderly group } \\
\mathrm{N}(\%)\end{array}$ & $P$ \\
\hline Surgery $(n=1094)^{a}$ & & & & 0.288 \\
\hline Yes & $1043(95.3)$ & $884(95.1)$ & $159(97.0)$ & \\
\hline No & $51(4.7)$ & $46(4.9)$ & $5(3.0)$ & \\
\hline Adjuvant chemotherapy $(n=1043)^{b}$ & & & & $<0.001$ \\
\hline Yes & $717(68.7)$ & $660(74.7)$ & $57(35.8)$ & \\
\hline No & $326(31.3)$ & $224(25.3)$ & $102(64.2)$ & \\
\hline Neoadjuvant chemotherapy $(n=734)^{b}$ & & & & 0.063 \\
\hline Yes & $90(12.3)$ & $83(13.2)$ & $7(6.7)$ & \\
\hline No & $644(87.7)$ & $547(86.8)$ & 97 (93.3) & \\
\hline Radiotherapy $(n=453)^{b}$ & & & & 0.006 \\
\hline Yes & $134(29.6)$ & $126(31.8)$ & $8(14.0)$ & \\
\hline No & $319(70.4)$ & $270(68.2)$ & $49(86.0)$ & \\
\hline $\begin{array}{l}\text { Endocrine therapy in HR+ patients } \\
(n=732) \text { b }\end{array}$ & & & & 0.978 \\
\hline Yes & $599(81.8)$ & $505(81.8)$ & $94(81.7)$ & \\
\hline No & $133(18.2)$ & $112(18.2)$ & $21(18.3)$ & \\
\hline Anti-HER2 therapy in HER2+ patients $(n=143)^{b}$ & & & & 0.609 \\
\hline Yes & $53(37.1)$ & $48(37.8)$ & $5(31.3)$ & \\
\hline No & $90(62.9)$ & $79(62.2)$ & $11(68.8)$ & \\
\hline
\end{tabular}

$H R$ hormone receptor, HER2 human epidermal growth factor receptor 2

a: All patients were included in the analysis

b: Only operated patients were included in the analysis

in the elderly group. Neoadjuvant chemotherapy was not associated with survival in multivariate analysis (OS: HR 1.430, 95\% CI 0.791-2.587, $P=0.237$, Table 4; DFS: Additional file 1: Table S2).

\section{Radiotherapy}

Among the patients who underwent mastectomy, we evaluated the role of adjuvant radiotherapy in older patients with positive-lymph node diseases $(n=453)$. Of these, only 134 (29.6\%) patients received postmastectomy radiotherapy, and the older group was more likely to receive adjuvant radiotherapy compared with the elderly group ( $31.8 \%$ vs. $14.0 \%$ respectively, $P=0.006$, Table $3)$. In the survival analysis, radiotherapy did not confer a benefit in OS, DFS or LRFS on these patients (Fig. 1c and Additional file 2: Fig. S1C). Moreover, receipt of radiotherapy had no impact on OS, DFS and LRFS in all subgroups (Fig. 2c and Additional file 2: Fig. S2C). After adjusting for the potential confounding factors, however, adjuvant radiotherapy following mastectomy showed a significant effect on LRFS, but not OS and DFS. (LRFS: HR 0.247, 95\% CI 0.072-0.839, $P=0.025$; OS: HR 0.733, 95\% CI 0.415-1.295, $P=0.285$, Table 4; DFS: Additional file 1: Table S2).

\section{Endocrine therapy}

We examined the effect of adjuvant endocrine therapy on survival in older patients with HR-positive breast cancer. Elderly group patients were as likely to be treated with endocrine therapy as those in older group, and the proportion of receiving endocrine therapy were high for both groups $(81.7 \%$ vs $81.8 \%$ respectively, $P=$ 0.978 , Table 3). Notably, endocrine therapy conferred a significant survival benefit on $\mathrm{HR}+$ patients (Fig. $1 \mathrm{~d}$ and Additional file 2: Fig. S1D). However, in subgroup analysis, endocrine therapy could provide a significant survival benefit for the older group, but not for the elderly group (Fig. 2d and Additional file 2: Fig. S2D). After adjusting for confounding factors, adjuvant endocrine therapy was indeed an effective treatment option in HRpositive older breast cancer patients (OS: HR 0.440, 95\% CI 0.261-0.741, $P=0.002$, Table 4; DFS: Additional file 1: Table S2).

Stratified analyses were conducted to determine which group of patients would benefit from additional chemotherapy based on endocrine therapy. Among HR-positive patients who received endocrine therapy, patients diagnosed at grade III or with high Ki-67 level were more likely to benefit from additional chemotherapy in terms of OS (OS: HR 0.305, 95\% CI 


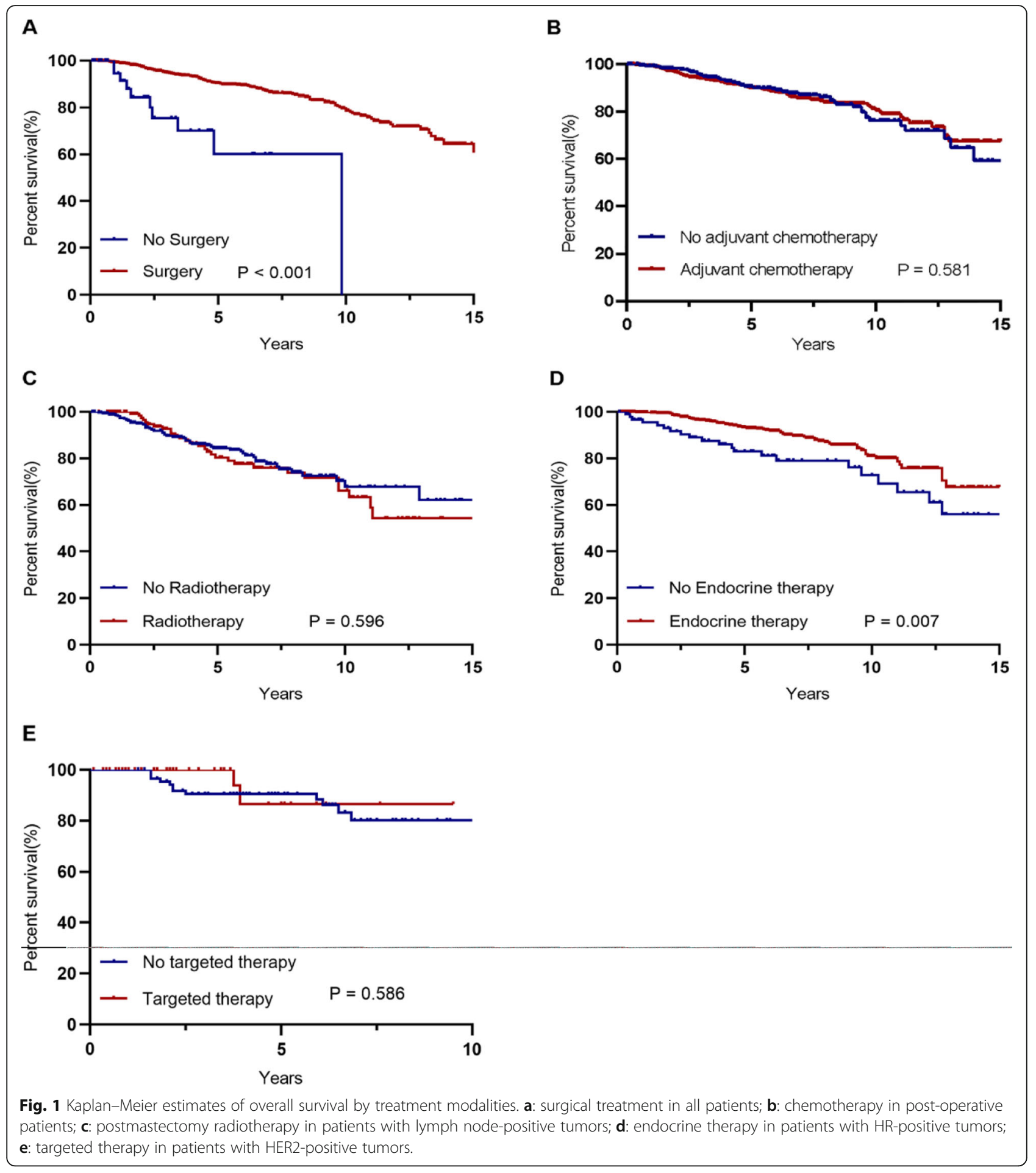

0.107-0.871, $P=0.019$, Fig. 2e; DFS: Additional file 2: Fig. S2E).

\section{Targeted therapy}

We analyzed the efficacy of trastuzumab therapy in HER2-positive breast cancer patients $(n=143)$, approximately one-third of patients received trastuzumab treatment. And no difference was observed in the proportion of patients receiving trastuzumab between two groups (Table 3). In the survival analysis, there was no significant difference in survival between patients treated with trastuzumab and those who did not (Fig. 1e and Additional file 2: Fig. S1E). In multivariate analysis, however, receipt of trastuzumab was associated with a lower 


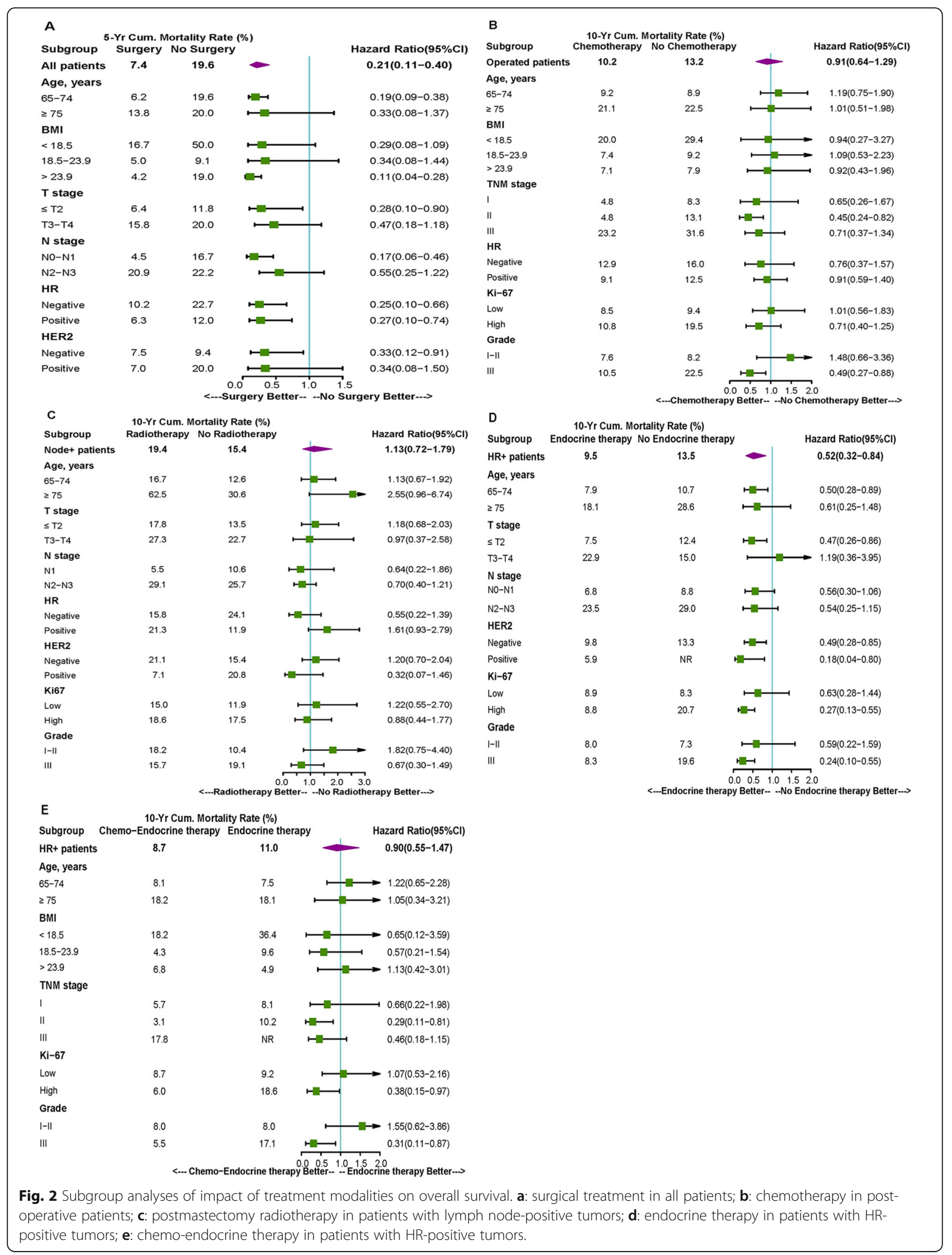


Table 4 Multivariate analysis of the effect of treatment on overall survival in different population

\begin{tabular}{|c|c|c|c|}
\hline Treatment & Population & $\mathrm{HR}^{\mathrm{a}}(95 \% \mathrm{Cl})$ & P-value \\
\hline Surgery (yes vs. no) & all patients & $0.476(0.250-0.904)$ & 0.023 \\
\hline $\begin{array}{l}\text { Adjuvant chemotherapy } \\
\text { (yes vs. no) }\end{array}$ & post-operative patients & $0.521(0.284-0.955)$ & 0.035 \\
\hline $\begin{array}{l}\text { Neoadjuvant chemotherapy } \\
\text { (yes vs. no) }\end{array}$ & stage II or III patients & $1.430(0.791-2.587)$ & 0.237 \\
\hline Radiotherapy (yes vs. no) & lymph node+ patients & $0.733(0.415-1.295)$ & 0.285 \\
\hline $\begin{array}{l}\text { Endocrine therapy } \\
\text { (yes vs. no) }\end{array}$ & HR+ patients & $0.440(0.261-0.741)$ & 0.002 \\
\hline $\begin{array}{l}\text { Targeted therapy } \\
\text { (yes vs. no) }\end{array}$ & HER2+ patients & $0.168(0.029-0.958)$ & 0.045 \\
\hline
\end{tabular}

$H R$ hormone receptor, $H E R 2$ human epidermal growth factor receptor 2; $\mathrm{HR}^{\mathrm{a}}$, hazard ratio; $95 \% \mathrm{Cl}, 95 \%$ confidence interval Multivariate analyses were adjusted for age, clinical stage, HR, HER2, tumor grade, treatment types

risk of mortality for HER2-positive patients after adjustment for multiple confounders (OS: HR 0.168, 95\% CI $0.029-0.958, P=0.045$, Table 4; DFS: Additional file 1: Table S2).

\section{Discussion}

Despite an increase in the number of older breast cancer patients [5], the optimal treatment modality for this population is still a challenging subject. Women aged 65 years and older have been underrepresented in cancer clinical trials $[17,18]$. As a consequence, the treatment guidelines for older breast cancer patients are less definitive compared with their younger counterparts due to the paucity of convincing data. Some scholars believe that less intensive treatments for older patients may not decrease their survival compared with standard treatments $[7,19]$. However, many published studies showed that less aggressive treatment for older women with early-stage breast cancer seemed to be associated with decreased survival $[8,20]$. Where prospective randomized trials are difficult to recruit older patients, a rigorous observational study with a large cohort might be of value for assessing the effect of different therapies on the elderly population, and could provide important guidance for clinical treatment decisions [19]. In the present study, we reviewed the tumor characteristics, real-world treatment patterns and survival outcomes of older patients with early breast cancer at a large tertiary academic medical center.

We comprehensively described the demographic and tumor characteristics of older patients with breast cancer. In this study, older patients more often presented with positive-HR status and negative-HER2 status. This finding was in accord with previous studies, older patients were usually diagnosed with more favorable tumor biology in contrast to young patients [8, 21, 22]. Tumor characteristics were similar between two age groups. However, elderly group patients were more likely to be underweight compared with older group, which implied that functional status declined with age. Moreover, we found that older age at diagnosis was associated with higher risk of mortality, independent of tumor characteristics and treatment. Previous studies also revealed that increasing age was associated with a higher diseasespecific mortality [23]. Paradoxically, older women generally have more favorable tumor biology, but they have worse breast cancer-specific mortality. The reasons for this include undertreatment, limited data from clinical trials and reduced age-related immune surveillance [24].

In this cohort, the majority of older patients underwent surgery, even in patients over 75 years of age. And almost all patients received mastectomy rather than breast conserving surgery. Some studies reported that older patients were more likely to receive mastectomy compared with lumpectomy $[25,26]$, which was consistent with our result. This may be because older patients were less critical of cosmetic appearance, or to avoid radiation therapy. In addition, we found that surgical treatment was associated with better survival, possibly because of a more advanced stage at diagnosis in nonsurgery patients. Of the patients who did not receive surgery, $78.4 \%$ received chemotherapy. Moreover, survival benefit of surgical treatment in patients older than 80 years have also been confirmed in another study [27], and surgical treatment was safe in older patients.

Adjuvant systemic chemotherapy is an effective treatment modality for young breast cancer patients [28], most patients in our cohort also received adjuvant chemotherapy. However, the proportion of patients treated with chemotherapy decreased with age, which could be explained by the fact that older patients had more comorbidities and concerned about the toxicity of chemotherapy [29, 30]. Limited researches focused on elderly breast cancer patients showed that adjuvant chemotherapy was associated with improved survival in patients at high risk of recurrence [31, 32]. In agreement, our results revealed that adjuvant chemotherapy could confer a survival benefit on patients with grade III or 
stage II disease. The lack of survival benefit of chemotherapy in stage-III patients may be due to the insufficient number of stage-III patients to produce significant result. Furthermore, we evaluated the role of neoadjuvant chemotherapy in elderly breast cancer patients staged at II-III. The neoadjuvant chemotherapy was less often used and did not offer any benefit to older patients in our cohort, which was seen in previous studies, where neoadjuvant chemotherapy seemed to be an uncommon option and had a lower pathologic complete response rate [33-35].

Postmastectomy radiotherapy (PMRT) was shown to reduce the risks of both recurrence and breast cancer mortality in all patients with node-positive breast cancer considered together [36]. In addition, women aged 70+ years seemed to have similar or higher postmastectomy LRR risks compared to younger women [37]. Therefore, we evaluated the use of PMRT and its impact on older patients with positive-lymph node disease in our cohort. PMRT was given to $31.8 \%$ of the patients aged 65 to 74 years, and $14.0 \%$ of the patients aged $\geq 75$ years. In clinical practice, there is a prevalent trend and demand to reduce use of postmastectomy radiotherapy in older patients [38]. The decline in use of PMRT among elderly group patients may be due to more comorbidities and concerns about the toxicity of radiotherapy [39]. However, it's worth noting that PMRT showed a significant effect on LRFS, but not OS and DFS, in older patients with lymph node-positive breast cancer in this study. For women with T1-2 breast cancer and one to two positive axillary lymph nodes, it was also reported that PMRT appeared to be associated with improvement in OS in older patients, but not younger patients [40]. These findings may inform future research direction whether elderly female patients with early breast cancer should receive postmastectomy radiotherapy.

Among HR-positive older patients, the proportion of the elderly group who accepted endocrine therapy was similar to that of older group in our current study. In contrast, several studies reported that women aged $>75$ years were less likely to receive endocrine therapy compared with younger patients [41, 42]. As we expected, endocrine therapy might be effective in improving overall survival in older patients with $\mathrm{HR}+$ breast cancer. However, subgroup analysis revealed endocrine therapy could improve OS and DFS in patients aged 65 to 74 years, while patients older than 75 years could not benefit from endocrine therapy. This finding might be caused by lower adherence and shorter duration of endocrine treatment in patients over 75 years old [43]. Furthermore, we found that among HR-positive patients who received endocrine therapy, those with grade III tumors or high Ki-67 level could benefit from additional chemotherapy. It seemed that HR-positive elderly breast cancer patients with high risk of recurrence could benefit from endocrine therapy combined with chemotherapy. Given this result, oncologist may need to consider more treatment choices for elderly HR-positive breast cancer patients with high recurrence risk.

In addition, we described the use and outcome of trastuzumab treatment among older women with HER2positive breast cancer. Only one third of HER2+ patients received trastuzumab treatment in this cohort, this finding was in line with recent data, they observed that the low utilization of adjuvant trastuzumab for older patients with HER2-positive disease [44]. However, trastuzumab was an effective therapy for HER2-positive breast cancer, with dramatically improved survival, regardless of age [45]. Our study also suggested that use of trastuzumab could reduce the risk of mortality in older patients.

This study had some limitations. Our study did not contain information on treatment-related complications, functional status, patient preference and quality of life, which may affect choice of treatment and survival outcomes. Our findings were based on a large cohort from a single center, thus need further verification in independent data sets.

\section{Conclusions}

In this large cohort, we found that surgical treatment remains a routine and curative option for older patients with early breast cancer. In the adjuvant setting, use of chemotherapy in older patients at high risk of recurrence (grade III or higher stage) was associated with improved survival. And endocrine therapy in HR-positive breast cancer patients and trastuzumab in HER2-positive breast cancer patients may be associated with reduced risk of mortality. We didn't find neoadjuvant chemotherapy or postmastectomy radiotherapy conferred significant OS or DFS benefit on older breast cancer patients. Moreover, prognostic clinicopathological characteristics should be comprehensively considered when making treatment decisions for those patients.

\section{Abbreviations \\ BCIMS: Breast Cancer Information Management System; BMI: Body mass index; Cl: Confidence interval; DCIS: Ductal carcinoma in situ; ER: Estrogen receptor; HER2: Human epidermal growth factor receptor-2; HR: Hormone receptor or hazard ratio; IDC: Invasive ductal carcinoma; LRFS: Locoregional recurrence-free survival; LRR: Locoregional recurrence; N stage: Nodal stage; OS: Overall survival; PMRT: Postmastectomy radiotherapy; PR: Progesterone receptor; T stage: Tumor stage}

\section{Supplementary Information}

The online version contains supplementary material available at https://doi. org/10.1186/s12885-021-07947-w.

Additional file 1: Table S1. Univariate and multivariate analysis of disease free survival in all breast cancer patients. Table S2. Multivariate analysis of the effect of treatment on disease free survival in different population. 
Additional file 2: Fig. S1. Kaplan-Meier estimates of disease free survival by treatment modalities. Fig. S2. Subgroup analyses of impact of treatment modalities on disease free survival.

\section{Acknowledgments}

We thank all staff members working on the Breast Cancer Information Management System (BCIMS) for their contributions to data collection and management.

\section{Authors' contributions}

$H Z$, XRZ, and $X L$ significantly contributed to the study design. $X R Z$ and $X L$ contributed to data acquisition, $X L$ performed data analyses, and $X L, D Z$, $Y Q W$, and $C X L$ interpreted the results. The manuscript was drafted by $X L$, and $Y F, X R Z, H Z$, and $X L$ revised the manuscript drafts critically. All authors read and approved the final manuscript.

\section{Funding}

This work was supported by the key program of the Science and Technology Department of Sichuan Province (grant number: 2017SZ0005; to H. Zheng).

\section{Availability of data and materials}

The datasets used and/or analysed during the current study are available from the corresponding author on reasonable request.

\section{Declaration}

\section{Ethics approval and consent to participate}

This study is approved by the Clinical Test and Biomedical Ethics Committee at West China Hospital, Sichuan University (reference number 2012-130). Informed consent was obtained from all patients. And all methods were performed in accordance with the Declaration of Helsinki.

\section{Consent for publication}

Not applicable.

\section{Competing interests}

The authors declare that they have no competing interests.

\section{Author details}

${ }^{1}$ Laboratory of Molecular Diagnosis of Cancer, Clinical Research Center for Breast, West China Hospital, Sichuan University, Chengdu, China. 2Department of Head, Neck and Mammary Gland Oncology, Cancer Center, West China Hospital, Sichuan University, Chengdu, China.

\section{Received: 15 November 2020 Accepted: 19 February 2021}

\section{Published online: 05 March 2021}

\section{References}

1. Bray F, Ferlay J, Soerjomataram I, Siegel RL, Torre LA, Jemal A. Global cancer statistics 2018: GLOBOCAN estimates of incidence and mortality worldwide for 36 cancers in 185 countries. CA Cancer J Clin. 2018;68(6):394-424.

2. Zheng RS, Sun KX, Zhang SW, Zeng HM, Zou XN, Chen R, et al. Report of cancer epidemiology in China, 2015. Zhonghua zhong liu za zhi [Chin J Oncol]. 2019;41(1):19-28.

3. Jia M, Zheng $\mathrm{R}$, Zhang $\mathrm{S}$, Zeng $\mathrm{H}$, Zou X, Chen W. Female breast cancer incidence and mortality in 2011, China. J Thoracic Dis. 2015;7(7):1221-6.

4. Li T, Mello-Thoms C, Brennan PC. Descriptive epidemiology of breast cancer in China: incidence, mortality, survival and prevalence. Breast Cancer Res Treat. 2016:159(3):395-406.

5. Fan L, Strasser-Weippl K, Li JJ, St Louis J, Finkelstein DM, Yu KD, et al. Breast cancer in China. Lancet Oncol. 2014;15(7):e279-89.

6. Scher KS, Hurria A. Under-representation of older adults in cancer registration trials: known problem, little progress. J Clin Oncol. 2012;30(17): 2036-8

7. Bastiaannet E, Portielje JE, van de Velde CJ, de Craen AJ, van der Velde S, Kuppen PJ, et al. Lack of survival gain for elderly women with breast cancer. Oncologist. 2011;16(4):415-23.

8. Bastiaannet E, Liefers GJ, de Craen AJ, Kuppen PJ, van de Water W, Portielje $\mathrm{JE}$, et al. Breast cancer in elderly compared to younger patients in the
Netherlands: stage at diagnosis, treatment and survival in 127,805 unselected patients. Breast Cancer Res Treat. 2010:124(3):801-7.

9. Schonberg MA, Marcantonio ER, Li D, Silliman RA, Ngo L, McCarthy EP. Breast cancer among the oldest old: tumor characteristics, treatment choices, and survival. J Clin Oncol. 2010;28(12):2038-45.

10. DeSantis CE, Miller KD, Dale W, Mohile SG, Cohen HJ, Leach CR, et al. Cancer statistics for adults aged 85 years and older, 2019. CA Cancer J Clin. 2019; 69(6):452-67.

11. Xie $Y$, Valdimarsdottir UA, Wang C, Zhong X, Gou Q, Zheng $H$, et al. Public health insurance and cancer-specific mortality risk among patients with breast cancer: a prospective cohort study in China. Int J Cancer. 2021;148(1): 28-37.

12. Group of China Obesity Task Force. Guidelines for prevention and control of overweight and obesity in Chinese adults. Acta Nutrimenta Sinica. 2004; 26(1):1-4.

13. Guideline Recommendations for Immunohistochemistry Detection in Breast Cancer Group. Guideline for testing of estrogen and progesterone receptors in breast cancer. Zhonghua bing li xue za zhi = Chinese journal of pathology. 2015:44(4):237-9.

14. Guideline Recommendations for HER2 Detection in Breast Cancer Group. Guidelines for HER2 detection in breast cancer, the 2014 version. Zhonghua bing li xue za zhi = Chinese journal of pathology. 2014;43(4):262-7.

15. Luo C, Zhong X, Deng L, Xie Y, Hu K, Zheng H. Nomogram predicting Locoregional recurrence to assist decision-making of Postmastectomy radiation therapy in patients with T1-2N1 breast Cancer. Int J Radiat Oncol Biol Phys. 2019;103(4):905-12.

16. Jwa $\mathrm{E}$, Shin KH, Lim HW, Jung SY, Lee $\mathrm{S}$, Kang HS, et al. Identification of risk factors for locoregional recurrence in breast cancer patients with nodal Stage N0 and N1: who could benefit from post-mastectomy radiotherapy? Plos One. 2015;10(12):e0145463.

17. Lewis JH, Kilgore ML, Goldman DP, Trimble EL, Kaplan R, Montello MJ, et al. Participation of patients 65 years of age or older in cancer clinical trials. J Clin Oncol. 2003;21(7):1383-9.

18. Townsley CA, Selby R, Siu LL. Systematic review of barriers to the recruitment of older patients with cancer onto clinical trials. J Clin Oncol. 2005:23(13):3112-24

19. Reeder-Hayes KE, Meyer AM, Hinton SP, Meng K, Carey LA, Dusetzina SB. Comparative toxicity and effectiveness of Trastuzumab-based chemotherapy regimens in older women with early-stage breast Cancer. J Clin Oncol.. 2017;35(29):3298-305.

20. Muss HB, Berry DA, Cirrincione CT, Theodoulou M, Mauer AM, Kornblith AB, et al. Adjuvant chemotherapy in older women with early-stage breast cancer. N Engl J Med. 2009;360(20):2055-65.

21. Fredholm H, Eaker S, Frisell J, Holmberg L, Fredriksson I, Lindman H. Breast cancer in young women: poor survival despite intensive treatment. PLoS One. 2009;4(11):e7695.

22. Maggard MA, O'Connell JB, Lane KE, Liu JH, Etzioni DA, Ko CY. Do young breast cancer patients have worse outcomes? J Surg Res. 2003;113(1):109-13

23. van de Water W, Markopoulos C, van de Velde CJ, Seynaeve C, Hasenburg $A$, Rea D, et al. Association between age at diagnosis and disease-specific mortality among postmenopausal women with hormone receptor-positive breast cancer. Jama. 2012;307(6):590-7.

24. Schwartzberg LS, Blair SL. Strategies for the Management of Early-Stage Breast Cancer in older women. J Nat Comprehensive Cancer Network. 2016; 14(5 Suppl):647-50.

25. Grumpelt AM, Ignatov A, Tchaikovski SN, Burger E, Costa SD, Eggemann H. Tumor characteristics and therapy of elderly patients with breast cancer. J Cancer Res Clin Oncol. 2016;142(5):1109-16.

26. Feigelson HS, James TA, Single RM, Onitilo AA, Aiello Bowles EJ, Barney T, et al. Factors associated with the frequency of initial total mastectomy: results of a multi-institutional study. J Am Coll Surg. 2013;216(5):966-75.

27. Ojala K, Meretoja TJ, Mattson J, Leidenius MHK. Surgical treatment and prognosis of breast cancer in elderly - a population-based study. Ejso-Eur J Surg Onc. 2019:45(6):956-62.

28. Abe O, Abe R, Enomoto K, Kikuchi K, Koyama H, Masuda H, et al. Effects of chemotherapy and hormonal therapy for early breast cancer on recurrence and 15-year survival: an overview of the randomised trials. Lancet. 2005; 365(9472):1687-717.

29. Patt DA, Duan Z, Fang S, Hortobagyi GN, Giordano SH. Acute myeloid leukemia after adjuvant breast cancer therapy in older women: understanding risk. J Clin Oncol. 2007;25(25):3871-6. 
30. Giordano SH, Pinder M, Duan Z, Hortobagyi G, Goodwin J. Congestive heart failure (CHF) in older women treated with anthracycline (A) chemotherapy (C). J Clin Oncol. 2006;24(18):8s.

31. Giordano SH, Duan ZG, Kuo YF, Hortobagyi GN, Goodwin JS. Use and outcomes of adjuvant chemotherapy in older women with breast cancer. J Clin Oncol. 2006;24(18):2750-6.

32. Ward SE, Holmes GR, Ring A, Richards D, Morgan JL, Broggio JW, et al. Adjuvant chemotherapy for breast Cancer in older women: an analysis of retrospective English Cancer registration data. Clin Oncol-Uk. 2019;31(7): 444-52.

33. Loibl S, von Minckwitz G, Untch M, Denkert C, Grp GB. Predictive factors for response to Neoadjuvant therapy in breast Cancer. Oncol Res Treat. 2014; 37(10):563-8.

34. Halfter K, Ditsch N, Kolberg HC, Fischer H, Hauzenberger T, von Koch FE, et al. Prospective cohort study using the breast cancer spheroid model as a predictor for response to neoadjuvant therapy - the SpheroNEO study. BMC Cancer. 2015;15:519.

35. von Waldenfels G, Loibl S, Furlanetto J, Machleidt A, Lederer B, Denkert C, et al. Outcome after neoadjuvant chemotherapy in elderly breast cancer patients - a pooled analysis of individual patient data from eight prospectively randomized controlled trials. Oncotarget. 2018;9(20):15168-79.

36. McGale P, Taylor C, Correa C, Cutter D, Duane F, Ewertz M, et al. Effect of radiotherapy after mastectomy and axillary surgery on 10-year recurrence and 20-year breast cancer mortality: meta-analysis of individual patient data for 8135 women in 22 randomised trials. Lancet (London, England). 2014; 383(9935):2127-35.

37. Truong PT, Lee J, Kader HA, Speers CH, Olivotto IA. Locoregional recurrence risks in elderly breast cancer patients treated with mastectomy without adjuvant radiotherapy. Eur J Cancer. 2005;41(9):1267-77.

38. Yancik R, Wesley MN, Ries LA, Havlik RJ, Edwards BK, Yates JW. Effect of age and comorbidity in postmenopausal breast cancer patients aged 55 years and older. Jama. 2001;285(7):885-92.

39. Chargari C, Kirov KM, Bollet MA, Magne N, Vedrine L, Cremades S, et al. Cardiac toxicity in breast cancer patients: from a fractional point of view to a global assessment. Cancer Treat Rev. 2011;37(4):321-30.

40. Bhutiani N, Egger ME, Stromberg AJ, Bhutiani IK, Ajkay N, McMasters KM. Identifying factors impacting the efficacy of postmastectomy radiotherapy in patients with early-stage breast cancer and one to two positive lymph nodes. J Surg Oncol. 2020;122(2):128-33.

41. Sant M, Meneghini E, Bastos J, Rossi PG, Guevara M, Innos K, et al. Endocrine treatment and incidence of relapse in women with oestrogen receptorpositive breast cancer in Europe: a population-based study. Breast Cancer Res Treat. 2020;183(2):439-50.

42. Jeon YW, You SH, Lee JE, Youn HJ, Lim W, Han JH, et al. Optimal treatment of breast cancer in women older than 75 years: a Korea breast Cancer registry analysis. Breast Cancer Res Treat. 2019;178(3):693-701.

43. Cavazza M, Banks H, Ercolanoni M, Cukaj G, Bianchi G, Capri G, et al. Factors influencing adherence to adjuvant endocrine therapy in breast cancertreated women: using real-world data to inform a switch from acute to chronic disease management. Breast Cancer Res Treat. 2020;183(1):189-99.

44. Freedman RA, Hughes ME, Ottesen RA, Weeks JC, He YL, Wong YN, et al. Use of adjuvant trastuzumab in women with human epidermal growth factor receptor 2 (HER2)-positive breast cancer by race/ethnicity and education within the National Comprehensive Cancer Network. Cancer. 2013;119(4):839-46.

45. Moja L, Tagliabue L, Balduzzi S, Parmelli E, Pistotti V, Guarneri V, et al. Trastuzumab containing regimens for early breast cancer. Cochrane Database Syst Rev. 2012;4:CD006243.

\section{Publisher's Note}

Springer Nature remains neutral with regard to jurisdictional claims in published maps and institutional affiliations.

Ready to submit your research? Choose BMC and benefit from:

- fast, convenient online submission

- thorough peer review by experienced researchers in your field

- rapid publication on acceptance

- support for research data, including large and complex data types

- gold Open Access which fosters wider collaboration and increased citations

- maximum visibility for your research: over $100 \mathrm{M}$ website views per year

At BMC, research is always in progress.

Learn more biomedcentral.com/submissions 